\title{
Controlling the neuronal balancing act: optical coactivation of excitation and inhibition in neuronal subdomains
}

\author{
Sarah Jarvis ${ }^{1 *}$, Konstantin Nikolic ${ }^{2}$, Nir Grossman², Simon R Schultz ${ }^{1}$ \\ From Twenty Second Annual Computational Neuroscience Meeting: CNS*2013 \\ Paris, France. 13-18 July 2013
}

Optogenetics provides a powerful tool with which to not only observe but also manipulate neuronal activity, due to the possibility to selectively activate spatially targeted subpopulations of neurons. Much focus has been placed on excitatory opsins, such as channelrhodopsin-2 (ChR2) [1], a light-gated cation channel which when illuminated locally depolarizes the neuron membrane and can illicit an action potential (optimal activation wavelength $\lambda=490 \mathrm{~nm}$ ). Previously, we investigated the effect of illuminating targeting spatially distinct subdomains of the neuron for cortical layer $\mathrm{V}$ pyramidal neurons [2]. We demonstrated that whole cell, rather than partial, illumination had the highest efficiency for producing an action potential.

More recently, the possibilities provided by ChR2 to probe the kinetics of action potential generation were further complemented by the development of silencing opsins that hyperpolarize the membrane, including halorhodopsin (NpHR) [3] and Archaerhodopsin T (ArchT) [4]. Both HR and ArchT have been demonstrated in vivo to silence activity for populations, but there has been little characterization of how they can be used to modulate action potential generation in individual neurons. As they can be illuminated independently of ChR2 (optimal activation wavelengths $\lambda=585,575$ for $\mathrm{NpHR}$ and ArchT respectively), together these two families of opsins provide a potential window through which to examine the interplay of competing excitatory and inhibitory inputs for differing spatial and temporal patterns of activation. Such characterization has implications for advancing our understanding of the non-linear

* Correspondence: s.jarvis@imperial.ac.uk

${ }^{1}$ Department of Bioengineering, Imperial College, London SW7 2AZ, UK

Full list of author information is available at the end of the article nature of inhibition, and is also vital for identifying effective protocols for silencing activity - especially while the spatial range and depth of illumination has experimental limitations that prevent deep or large areas being easily accessible. More importantly, it may allow more subtle changes to be made to neuronal function, for instance by altering the transfer function of genetically targeted classes of neurons.

Here, we present the results of study in which we have modeled neurons expressing NpHR and ArchT in NEURON. Using these models, we investigate common illumination strategies and examine the emergence of the subthreshold dynamics by simultaneously illuminating ChR2 and silencing opsins, both for disjoint and identical spatial locations. Finally, we activate silencing opsins while providing excitatory input via illumination of ChR2 in the proximal apical and basal dendrites, mimicking the location of excitatory presynaptic synapses in vivo. We demonstrate that it is possible to "reprogramme" the current-to-firing-rate transfer function of a neuron [5], altering both gain and threshold in either direction, by optical neuromodulation using a combination of ChR2 and ArchT or NpHR targeted to appropriate areas of the neuronal morphology. Using these results, we propose a more effective, targeted stimulation protocol for successfully inhibiting neuronal populations in cortical layers.

\section{Acknowledgements}

This work was supported by Wellcome Trust grant 097816/Z/11/A.

\section{Author details}

'Department of Bioengineering, Imperial College, London SW7 2AZ, UK.

${ }^{2}$ Institute of Biomedical Engineering, Department of Electrical and Electronic Engineering, Imperial College, London SW7 2AZ, UK.

Published: 8 July 2013 


\section{References}

1. Boyden ES, Zhang F, Bamberg E, Nagel G, Deisseroth K: Millisecondtimescale, genetically targeted optical control of neural activity. Nat Neurosci 2005, 8(9):1263-1268.

2. Grossman N, Simiaki V, Martinet C, Toumazou C, Schultz SR, Nikolic K: The spatial pattern of light determines the kinetics and modulates backpropagation of optogenetic action potentials. J Comp Neurosci 2012.

3. Han X, Boyden ES: Multiple-color optical activation, silencing, and desynchronization of neural activity, with single-spike temporal resolution. 2007, 2(3):e299, PLoS one.

4. Han X, Chow BY, Zhou H, Klapoetke NC, Chuong A, Rajimehr R, Yang A, Baratta MV, Winkle J, Desimone R, Boyden ES: A high-light sensitivity optical neural silencer: development and application to optogenetic control of non-human primate cortex. Front Systems Neurosci 2011, 5:18.

5. Chance FS, Abbott LF, Reyes AD: Gain modulation from background synaptic input. Neuron 2002, 35:773-782.

doi:10.1186/1471-2202-14-S1-P348

Cite this article as: Jarvis et al:: Controlling the neuronal balancing act: optical coactivation of excitation and inhibition in neuronal subdomains. BMC Neuroscience 2013 14(Suppl 1):P348.

\section{Submit your next manuscript to BioMed Central} and take full advantage of:

- Convenient online submission

- Thorough peer review

- No space constraints or color figure charges

- Immediate publication on acceptance

- Inclusion in PubMed, CAS, Scopus and Google Scholar

- Research which is freely available for redistribution

Submit your manuscript at www.biomedcentral.com/submit
Ciomed Central 